\title{
The impact of bladder neck sparing on urinary continence during laparoscopic radical prostatectomy; Results from a high volume centre
}

\author{
Ali Serdar Gozen ${ }^{1}$, Yigit Akin ${ }^{2}$, Mutlu Ates ${ }^{3}$, Marcel Fiedler ${ }^{1}$, Jens Rassweiler ${ }^{1}$ \\ ${ }^{1}$ Department of Urology, SLK-Klinikum Heilbronn, University of Heidelberg, Heilbronn, Germany; \\ ${ }^{2}$ Department of Urology, Izmir Katip Celebi University School of Medicine, Izmir, Turkey; \\ ${ }^{3}$ Department of Urology, Antalya Teaching and Research Hospital, Antalya, Turkey.
}

\begin{abstract}
Summary Objective: To evaluate the effects of bladder neck reconstruction techniques on early continence after laparoscopic radical prostatectomy (LRP). Materials and methods: This non-randomized retrospective study analyzed prospectively collected data concerning LRP. In total, 3107 patients underwent LRP between March 1999 and December 2016. Exclusion criteria were preoperative urinary incontinence, previous history of external beam radiotherapy, co-morbities which may affect urinary continence such as diabetes mellitus and/or neurogenic disorders, irregular followup, and follow-up shorter than 24 months. All patients were divided into one of three groups, posterior reconstruction being performed in Group $1(n=112)$, anterior reconstruction in Group $2(n=762)$, and bladder neck sparing (BNS) in Group 3 $(n=987)$. Demographic and pre-, peri-, and postoperative data were collected. Multivariate analyses were performed to determine factors affecting early continence after LRP.

Results: 1861 patients were enrolled in the study. The mean follow-up period was $48.12 \pm 29.8$ months, and subjects' mean age was $63.6 \pm 6.2$ years. There was no significant difference among the groups in terms of demographic or preoperative data. Postoperative data, including oncological outcomes, were similar among the groups. The level of early continence was higher in Group 3 than in the other groups $(p<0.001)$.

Multivariate analyses identified BNS and age as parameters significantly affecting early continence levels after LRP $(p<0.001$ and $p<0.001$, respectively). Bladder neck reconstruction provided less earlier continence than BNS.
\end{abstract}

KEY WORDS: Bladder neck; Laparoscopy;

Surgery; Prostate cancer; Radical prostatectomy; Urinary continence.

Submitted 10 May 2017; Accepted 2 June 2017

\section{INTRODUCTION}

Prostate cancer (PCa) is the most common solid organ cancer among men worldwide (1). Although there are different ways to treat $\mathrm{PCa}$, radical prostatectomy (RP) is still the gold standard treatment modality for organ-confined PCa $(2,3)$. Nearly two-thirds of PCa cases are confined to the prostate and can be treated by RP (3). Recently, minimally invasive surgical techniques, such as laparoscopic radical prostatectomy (LRP) and robotic-assisted laparoscopic radical prostatectomy (RALP), have been successfully used as contemporary surgical options in organ-confined PCa with similar oncological and fuctional results (4). However, the RALP procedure, including the robotic device,is still expensive. LRP thus still assumes a more important place among surgical treatment options for PCa. Although LRP can provide the well-known advantages of laparoscopy, urinary incontinence is one of the main functional problems that can concern patients after surgery. In addition, incontinence has an adverse impact on quality of life and causes indirect workforce losses (5). Early continence is therefore important for rapid recovery after LRP. The level of continence ranges between $60 \%$ and $94 \%$ at short-term follow-ups $(6,7)$. This variation may be also due to different definitions of continence levels and different followup strategies. Various surgical modifications, such as bladder neck sparing (BNS), have been introduced for early continence $(8,9)$. However, in addition to surgical modifications for providing early continence, surgeons are also consistently developing new techniques for achieving continence in the light of improvements in endourological technology (10). Nonetheless, the exact factors affecting urinary continence after LRP have not yet been clearly defined. Additionally, to the best of our best knowledge, no comparison of techniques performed on the bladder neck, such as posterior reconstructions, anterior reconstructions and BNS, in LRP have to date been reported in the literature. The purpose of this study was to investigate BNS and bladder neck reconstruction techniques in term of providing early continence after LRP.

\section{Materials AND METHOdS}

This study represents a non-randomized retrospective view of prospectively collected data. All patients fully understood the treatment and aim of the study and provided written informed consent. All data were recorded prospectively on a Microsoft Office Excel spreadsheet. This series is part of an ongoing LRP project in our department.

\section{Patient selection}

We identified 3107 patients undergoing LRP due to organconfined PCa between March 1999 and December 2016. 
Exclusion criteria were preoperative urinary incontinence, previous history of external beam radiotherapy, comorbidities which may affect urinary continence, such as diabetes mellitus and/or neurogenic disorders, irregular follow-up, and a follow-up duration of less than 24 months. Finally, 1861 patients were enrolled into the study.

All LRP patients were divided into three groups depending on BNS or bladder neck reconstruction techniques in order to evaluating the impact of these on early continence after surgery. Group $1(\mathrm{n}=112)$ consisted of patients undergoing posterior reconstruction (dorsal reconstruction), Group 2 ( $\mathrm{n}=762$ ) of patients undergoing anterior reconstruction (ventral reconstruction), and Group 3 ( $n=987$ ) of patients undergoing BNS. Subgroups based on early and late continence status were also established. Factors affecting early continence were investigated.

\section{Data collection}

Patient data including age, body mass index (BMI), preoperative prostate specific antigen (PSA), previous operations, co-morbidities, clinical stage, operation time, surgical methods used for bladder neck reconstruction, nerve sparing surgery, estimated blood loss (EBL), prostate volume, length of hospital stay, duration of urethral catheter, histopathological and oncological outcomes and urinary continence rates were recorded. Potency was defined as erection sufficient for intercourse, with or without medication. Patients were administered International Index of Erectile Functions (IIEF) questionnaires, before and after surgery. Patients with IIEF-5 scores $\leq 11$ were regarded as having erectile dysfunction (ED).

\section{Surgical techniques}

The Heilbronn ascending LRP technique has been described previously in the literature $(11,12)$. Pelvic lymph node dissections were performed in an extended fashion for patients with PSA > $10 \mathrm{ng} / \mathrm{mL}$ and/or a Gleason score $>6$. Urethro-vesical anastomoses were performed with continuous sutures as described by van Velthoven, including reconstruction of the bladder neck (13).

\section{Posterior reconstruction technique}

This technique was used in cases with a large prostate, with a large median lobe, with a possible bladder neck invasion and in case of a previous transurethral resection of prostate (Group 1). The bladder neck should be reconstructed in these cases, after the necessary wide resection. Posterior reconstruction began from the distal and close to the trigonal part of bladder neck to the superior part of the bladder neck using a running suture (3/0 Vicryl-V-loc). The bladder neck should resemble a 'reverse tennis racquet' after the reconstruction (Figure 1), as reported by Sarle et al. (14) A DJ stenting was necessary in 3 cases. Anastomosis was performed after the bladder neck reconstruction using the Van Velthoven technique $(10,11)$.

\section{Anterior reconstruction technique}

This procedure was performed in the case of bladder neck was larger than urethral lumen (Group 2). Our aim was to reconstruct the bladder neck based on its unique anatomical structures (15). We closed the bladder neck in the form of figure-of-eight stitches, on the ventral side

\section{Figure 1.}

Posterior bladder neck reconstruction resembling a "reverse tennis racquet". The arrow shows the tip of the racquet.

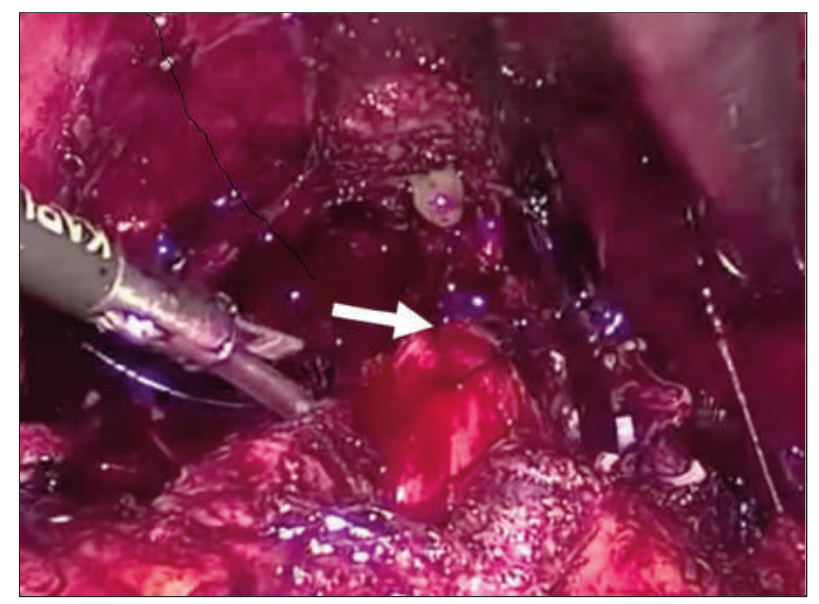

(12 o clock) (Figure 2.). The larger bladder neck has been adjusted in this way to the urethra.

\section{Figure 2.}

Anterior bladder neck reconstruction with "figure-of-eight" stitches on the ventral side of the bladder neck.

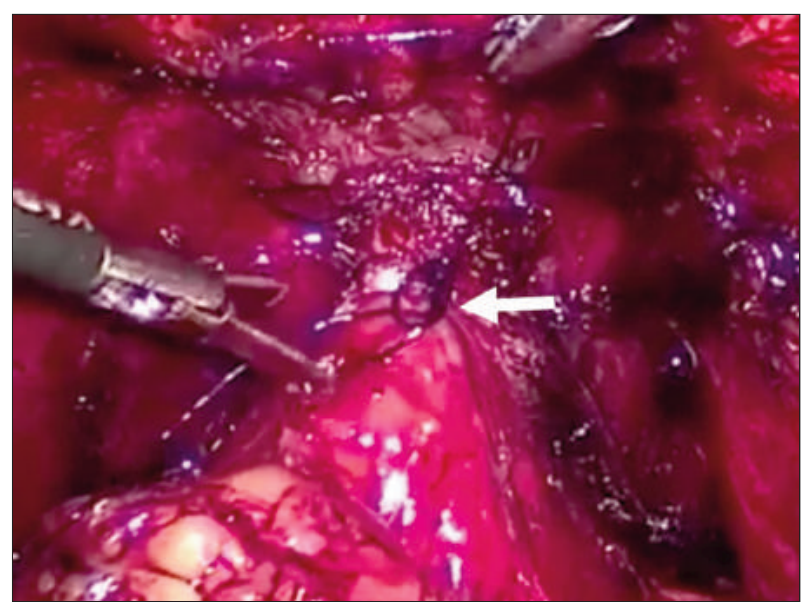

Bladder neck sparing technique

Group 3 consisted of patients undergoing a full bladder neck preservation. Briefly, the base of the prostate was hold to the ventral side by the application of traction to the urethral catheter balloon. The fatty space between the bladder and the anterior leaf of Denonvilliers' fascia was observed. Blunt dissections were then performed using a right-angle dissector around the bladder neck. The anterior wall of the bladder neck was incised thereafter horizontally, and careful stepwise dissections were performed around the catheter, thus exposing the muscle fibers of bladder neck (Figure 3.)

\section{Follow-up and continence status}

Cystography was performed in all cases, on the $7^{\text {th }}$ day of surgery. If no leak was determined, the urethral catheter was removed. All complications were classified according to the modified Clavien classification (16). Indications for 


\section{Figure 3.}

The bladder neck sparing surgical technique. Anatomical dissections were able to be performed to separate the bladder neck and prostate. The yellow arrows shows the neurovascular bundle.

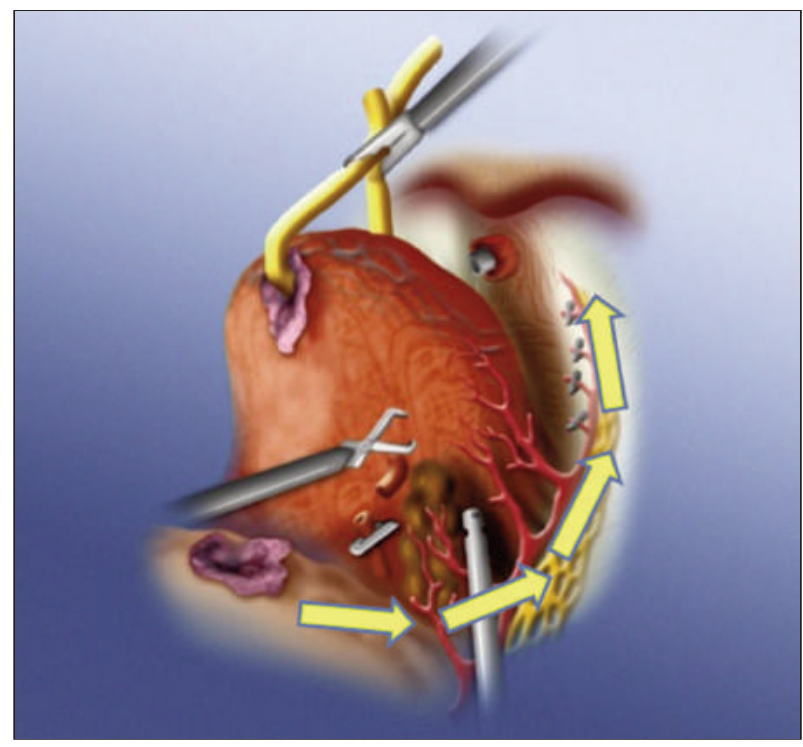

adjuvant hormone therapy and radiotherapy were determined using the Walz score (17). Self-administered modified International Continence Society questionnaires were used to evaluate early continence status. This was also evaluated by physical examination, including the Valsalva or cough stress tests. All patients were advised to perform Kegel's exercises after removal of the urinary catheter. No patients received any surgical treatment for stress urinary incontinence during 24-month follow-up after LRP. Safety pads were applied before the tests. Patients without urine leakage during coughing or sneezing, as well as those who stayed totally dry, were considered urinary continent. Patients who were consistently dry but used a safety pad occasionally during normal daily activity (ie, work, exercise, and walking) were considered continent. Patients who used more than one protective pad per day and/or who experienced urine leak during coughing, sneezing or nocturnally were considered incontinent. Time to continence was classified into two time intervals; early (within 3 months after LRP), and late continence (4-24 months after LRP). Continence status was evaluated at the $1^{\text {st }}$ and $3^{\text {rd }}$ month after LRP by physical examinations including the tests summarized above.

Continence status was then assessed at quarterly intervals within the first year and semi-annually thereafter. The BNS and reconstruction techniques, nerve sparing surgical techniques, clinical stage, BMI, age, prostate volume, duration of urethral catheter use, and oncological results were evaluated using multivariate analyses in order to determine the factors affecting continence.

All postoperative complications were evaluated based on modified Clavien-Dindo classifications (18).

\section{Statistical analysis}

Associations in the subgroups were examined using the Chi square, One Way Anova and Kruskal Wallis tests. Multivariate logistic regression analyses were performed to evaluate factors affecting early continence. All statistical tests were performed on Statistical Package for Social Sciences, version 16.0 (SPSS, Chicago, IL) software. Statistical significance was set at $\mathrm{p}<0.05$.

\section{RESULTS}

The mean follow-up period was $48.12 \pm 29.8$ months, and mean age was $63.6 \pm 6.2$ years. Mean values for demographic data are shown in Table 1 . No significant difference was determined among the groups in terms of demographic data. Parameters including mean PSA, clinical stage, and prostate volume were also comparable between the groups. These are summarized in Table 2. Operative and postoperative data are presented in Table 3.

No significant difference was determined between the groups in terms of operative time $(p<0.001)$. Levels of nerve sparing surgical techniques, EBL, hospital stay, and duration of catheterization were similar among the groups (Table 4).

\section{Table 1.}

Details of demographic and operative data.

\begin{tabular}{|l|c|}
\hline Parameter & Data \\
\hline Mean age & $63.9 \pm 6.2$ \\
\hline Mean BMI & $26.8 \pm 1.2$ \\
\hline Mean PSA & $10 \pm 3.7$ \\
\hline Mean prostate volume & $36.2 \pm 16.5$ \\
\hline BMI: Body mass index; PSA: Prostate specific antigen. \\
\hline
\end{tabular}

Table 2.

Perioperative results of groups.

\begin{tabular}{|c|c|c|c|c|c|}
\hline Parameter & & $\begin{array}{c}\text { Group } 1 \\
(n=112)\end{array}$ & $\begin{array}{c}\text { Group 2 } \\
(\mathrm{n}=762)\end{array}$ & $\begin{array}{c}\text { Group } 3 \\
(n=987)\end{array}$ & $\begin{array}{c}P \\
\text { value }\end{array}$ \\
\hline \multicolumn{6}{|c|}{ Mean age (years) } \\
\hline One way anova & & $64.5 \pm 5.9$ & $64 \pm 5.9$ & $63.7 \pm 6.4$ & 0.26 \\
\hline \multicolumn{6}{|l|}{ BMI $\left(\mathrm{kg} / \mathrm{m}^{2}\right)$} \\
\hline & $<25(n, \%)$ & $35(30.7 \%)$ & 242 (31.7\%) & 335 (33.6\%) & 0.76 \\
\hline \multirow[t]{2}{*}{ Chi square } & $25-30(n, \%)$ & $43(37.7 \%)$ & $283(37 \%)$ & 377 (37.8\%) & \\
\hline & $>30(n, \%)$ & $36(31.5 \%)$ & 238 (31.1\%) & $284(28.5 \%)$ & \\
\hline \multicolumn{6}{|c|}{ Mean PSA (ng/ml) } \\
\hline One way anova & $10 \pm 7$ & $9.8 \pm 6.4$ & $10.1 \pm 12.4$ & 0.86 & \\
\hline \multicolumn{6}{|c|}{ Clinical stage $(n, \%)$} \\
\hline \multirow[t]{3}{*}{ Chi square } & $\mathrm{T} 1$ & $22(19.2 \%)$ & $150(19.6 \%)$ & 231 (23.1\%) & 0.42 \\
\hline & $\mathrm{T} 2$ & $57(50 \%)$ & $367(48 \%)$ & $452(45.3 \%)$ & \\
\hline & T3 & $35(30.7 \%)$ & $246(24.6 \%)$ & $313(31.4 \%)$ & \\
\hline \multicolumn{6}{|c|}{ Prostate volume (cc) (n, \%) } \\
\hline \multirow[t]{2}{*}{ Chi square } & $\leq 50$ & $93(81.5 \%)$ & 637 (83.4\%) & $844(84.7 \%)$ & 0.59 \\
\hline & $>50$ & $21(18.4 \%)$ & $126(16.5 \%)$ & $152(15.2 \%)$ & \\
\hline \multicolumn{6}{|c|}{ Mean prostat volume } \\
\hline One way anova) & & $38.6 \pm 18.8$ & $35.6 \pm 18$ & $36.4 \pm 14.9$ & 0.15 \\
\hline
\end{tabular}


Table 3.

Details of operative and postoperative data.

\begin{tabular}{|l|c|}
\hline Parameter & Data \\
\hline Mean operation time & $212.3 \pm 43.4$ \\
\hline Mean EBL & $828.4 \pm 440.6$ \\
\hline Mean hospital stay & $10.2 \pm 4.5$ \\
\hline Mean duration of catheter & $9.4 \pm 4.9$ \\
\hline Continence & $n=1753,94.1 \%$ \\
\hline Biochemical recurrence & $n=337,18.1 \%$ \\
\hline EBL: Estimated blood loss. & \\
\hline
\end{tabular}

gical techniques with large numbers of patients, after LRP have to date been available. Additionally, the exact factors involved in the provision of early continence had not been identified. To the best of our knowledge, this is the first series with large patient numbers to investigate early continence was investigated after LRP in terms of BNS and bladder neck reconstruction techniques. On the basis of our results, bladder neck reconstruction techniques (Group 1 and Group 2) provided similar continence levels. High levels of early urinary continence were achieved with BNS in younger patients after LRP.
No significant difference were also determined in terms of pathological findings, including pathological stage, Gleason score, positive surgical margins, and biochemical recurrence.

Complication rates were similar in the groups (Table 5). Forty-two (36.8\%) patients in Group 1.374 (49\%) patients in Group 2 and 601 (60.3\%) patients in Group 3 were continent 3 months after LRP.
Table 4.

Peri and postoperative results of groups.

\begin{tabular}{|lcccc|}
\hline Parameter & $\begin{array}{c}\text { Group 1 } \\
(\mathbf{n}=\mathbf{1 1 2})\end{array}$ & $\begin{array}{c}\text { Group 2 } \\
(\mathbf{n}=\mathbf{7 6 3})\end{array}$ & $\begin{array}{c}\text { Group 3 } \\
(\mathbf{n}=\mathbf{9 9 6 )}\end{array}$ & $\begin{array}{c}\mathbf{P} \\
\text { value }\end{array}$ \\
\hline Mean operation time (min.) & $212 \pm 45$ & $217.3 \pm 45.8$ & $208.5 \pm 41$ & $<0.001^{*}$ \\
\hline Nerve sparing surgery (n,\%) & $54(47.3 \%)$ & $375(49.1 \%)$ & $432(43.3 \%)$ & 0.052 \\
\hline Mean EBL (ml) & $775.4 \pm 352.6$ & $824.7 \pm 468.4$ & $837.2 \pm 427.5$ & 0.34 \\
\hline Mean Hospital stay (day) & $9.7 \pm 2.8$ & $10.3 \pm 3.3$ & $10.3 \pm 5.4$ & 0.41 \\
\hline Mean duration of catheter (day) & $9.1 \pm 4.1$ & $9.4 \pm 4.8$ & $9.4 \pm 5$ & 0.86 \\
\hline Abbreviations: EBL: Estimated blood loss *Statistical signifiant $p$ value. & \\
\hline
\end{tabular}

Table 5.

Oncological and functional results of groups.

\begin{tabular}{|c|c|c|c|c|c|}
\hline Parameter & & $\begin{array}{l}\text { Group } 1 \\
(n=114)\end{array}$ & $\begin{array}{l}\text { Group } 2 \\
(n=763)\end{array}$ & $\begin{array}{l}\text { Group } 3 \\
(n=996)\end{array}$ & $\begin{array}{c}P \\
\text { value }\end{array}$ \\
\hline$\overline{\mathrm{pT}}$ & $\begin{array}{l}\text { pT0-2 } \\
\text { pT3-4 }\end{array}$ & $\begin{array}{l}64(56.1 \%) \\
50(43.8 \%)\end{array}$ & $\begin{array}{c}474(62.1 \%) \\
289(37.8)\end{array}$ & $\begin{array}{l}594(59.6 \%) \\
402(40.3 \%)\end{array}$ & 0.35 \\
\hline $\begin{array}{l}\text { Mean prostate } \\
\text { volume (cc) }\end{array}$ & & $44.8 \pm 20.4$ & $44.4 \pm 18.3$ & $43.6 \pm 17$ & 0.59 \\
\hline $\begin{array}{l}\text { Mean pathological } \\
\text { Gleason acore (n, \%) }\end{array}$ & $\begin{array}{c}<7 \\
7 \\
>7\end{array}$ & $\begin{array}{c}40(35 \%) \\
60(52.6 \%) \\
14(12.2 \%)\end{array}$ & $\begin{array}{c}340(44.5 \%) \\
348(45.6 \%) \\
75(9.8 \%)\end{array}$ & $\begin{array}{c}425(42.6 \%) \\
486(48.7 \%) \\
85(8.5 \%)\end{array}$ & 0.23 \\
\hline Pozitive surgical margin & & $34(29.8 \%)$ & $178(23.3 \%)$ & $237(23.7 \%)$ & 0.31 \\
\hline Early continence $(n, \%)$ & & $42(36.8 \%)$ & $374(49 \%)$ & $601(60.3 \%)$ & $<0.001 *$ \\
\hline Biochemical recurrence & & $21(18.4 \%)$ & $160(20.9 \%)$ & $196(19.6 \%)$ & 0.75 \\
\hline
\end{tabular}

Clinical stage, nerve sparing surgical technique, biochemical recurrence, and pathological stage did not significant affect early continence levels at multivariate analysis.

Stolzenburg et al. reported early continence using BNS after LRP (21). Chlosta et al. achieved similar results in their series of 194 LRP patients (22). Our series involved 987 (53\%) BNS patients, 601 (60.3\%) of whom were continent in the 3rd month of LRP. The BNS technique contributes a sphincter mechanism which includes striated and smooth muscle fibres (23).

Additionally, the striated muscle fibers in the urethra are horseshoe-shaped and these also assist with continence. However, urological stud-

Continence levels were similar between Group 1 (posterior reconstruction) and Group 2 (anterior reconstructions). The level of early continence was higher in Group 3 than in the bladder reconstruction groups $(p<0.001)$. At multivariate analyses, BNS and age were determined as parameters that significantly affected early continence levels after LRP $(p<0.001$ and $p<0.001$, respectively) (Table 6).

\section{Discussion}

Urinary continence is an essential parameter for early recovery after LRP (19). Surgical modifications have therefore been introduced in order to provide early continence after prostatectomy in patients with PCa. BNS and bladder neck reconstruction techniques can provide early continence after radical prostatectomy (20). All these surgical techniques can be performed during LRP, which includes the well-known benefits of laparoscopy (12). No published data, including comparisons of all sur-
Table 6.

Factors effecting early continence status in multivariate logistic regression analyses.

\begin{tabular}{|l|c|}
\hline Parameter & P value \\
\hline BNS surgical technique & $<0.001 *$ \\
\hline Anterior reconstruction & 0.3 \\
\hline Posterior reconstruction & 0.4 \\
\hline Clinical stage & 0.47 \\
\hline Age (year) & $<0.001 *$ \\
\hline BMI & 0.15 \\
\hline Prostate volume & 0.28 \\
\hline Preoperative PSA & 0.95 \\
\hline Operation time & 0.2 \\
\hline Nerve sparing surgical technique & 0.06 \\
\hline Duration of urethral catheter & 0.3 \\
\hline Surgical margin & 0.74 \\
\hline Biochemical recurrence & 0.55 \\
\hline BMI: Body mass index; BNS: Bladder neck sparing; \\
PSA: Prostate specific antigen *Statistical significant $p$ value \\
\hline
\end{tabular}


ies have shown that these cannot sustain contraction over $60 \mathrm{sec}$. $(24,25)$ Smooth muscle fibers of course assist continence. The BNS technique permits the smooth muscle fibers to remain place. We tried to perform as many BNS procedures in LRP cases as possible. During LRP, these fibers can be preserved more than with open surgical techniques through the well-known advantages of laparoscopy. Rosenblatt et al. reported that bladder neck reconstruction surgical techniques may be required by 10-15\% of LRP patients (26). Rocco et al. described a surgical technique for bladder neck reconstruction and reported early continence as one advantage of this (27). In another study, they reported no significant complications associated with the posterior musculofascial plate reconstruction technique, and described reconstruction of the posterior musculofascial plate as encouraging in terms of earlier continence recovery (27). Nevertheless, this subject is still controversial (28). Posterior reconstruction was performed in 114 (4.4\%) of our cases. The early continence level was 54\% in LRP patients, lower than that achieved with BNS (60.3\%). We performed posterior bladder neck reconstruction in 71 (6.1\%) cases. Daouacher and Walden recently described anterior and posterior reconstructions during LRP as safe and effective, without affecting voiding or surgical margins (29). In our recent series, anterior reconstruction was performed in 763 (40.9\%) cases. Both posterior and anterior reconstructions may provide early continence. However, the level of early continence was statistically significantly higher in Group 3 (BNS) than in the other groups. Poon et al. compared the outcomes of BNS with those of bladder neck repairing techniques as anterior and posterior reconstructions in a series of patients undergoing open radical prostatectomy (30). No significant difference was determined in early and late continence levels during follow-up. Our series differs from that of Poon et al. (30). The normal anatomy of the bladder neck was preserved by using laparoscopy in all patients in Group 3. Optic magnification of anatomical structures and the use of precision instruments may have contribute to the good results as well as the advanced laparoscopic techniques employed.

Katz et al. reported that a wide resection of the bladder neck can decrease positive margins on bladder neck (31). But, this may also have an adverse effect on continence after LRP. However, the positive surgical margin levels were similar among the groups in the present study. Additionally, a positive surgical margin did not emerge as a significant factor in early continence at multivariate analyses.

Multivariate analysis identified mean age as a factor affecting early continence. Kadono et al. reported age as a predictive factor for incontinence following minimally invasive surgical treatment of $\mathrm{PCa}$ (32). Kumar et al. investigated 3241 patients and concluded similar results (33). Our data are comparable with those previous studies, and early continence was adversely affected by advanced age. This raises the question of early detection of PCa. Robot-assisted laparoscopic prostatectomy (RALP) can provide more anatomical details for surgeons during surgery (25). BNS can thus be performed more accurately during RALP. Tunc et al. reported their early continence results after RALP by presenting a novel technique for BNS. Our results are parallel to those of their study. We think that superior magnification can improve surgeons techniques and learning curves (25). Early continence can thus be established after LRP/RALP, and this will in turn assist early recovery after surgery.

The main limitation of this study is that numbers of patients in the groups were not similar, because our surgical technique did not usually require bladder neck reconstructions (34). The aim of the present series is to compare BNS and bladder neck repairing techniques in LRP among large numbers of patients. To the best of our knowledge, this series is unique in the literature due to the features described.We recommend that surgeons make every effort to perform BNS during LRP.

\section{Conclusions}

Bladder neck reconstruction surgical techniques and BNS can provide good continence results after LRP. However, BNS is significantly superior to bladder neck reconstruction techniques in terms of establishing early continence after LRP, notably in younger patients. Additionally, BNS involved more anatomical dissections without altering oncological outcomes.. More standardized and multi-centered studies are now needed to optimize current surgical techniques for providing early continence after LRP.

\section{REFERENCES}

1. Jemal A, Bray F, Center MM, et al. Global cancer statistics. CA Cancer J Clin. 2011; 61:69-90.

2. Jemal A, Siegel R, Ward E, et al. Cancer statistics, CA Cancer J Clin. 2006; 56:106-30.

3. Basillote JB, Ahlering TE, Skarecky DW, et al. Laparoscopic radical prostatectomy: review and assessment of an emerging technique. Surg Endosc. 2004; 18:1694-711.

4. Ficarra V, Novara G, Rosen RC, et al. Systematic review and meta-analysis of studies reporting urinary continence recovery after robot-assisted radical prostatectomy. Eur Urol. 2012; 62:405-17.

5. MacDonald R, Fink HA, Huckabay C, et al. Pelvic floor muscle training to improve urinary incontinence after radical prostatectomy: a systematic review of effectiveness. BJU Int. 2007; 100:76-81.

6. Rassweiler J, Schulze M, Teber D, et al. Laparoscopic radical prostatectomy: Functional and oncological outcomes. Curr Opin Urol. 2004; 14:75-82.

7. Touijer K, Eastham JA, Secin FP, et al. Comprehensive prospective analysis of outcomes between open and laparoscopic radical prostatectomy conducted in 2003 to 2005. J Urol. 2008; 179: 1811-7.

8. Klein EA. Early continence after radical prostatectomy. J Urol. 1992; 148:92-5

9. Lowe BA. Comparison of bladder neck preservation to bladder neck resection in maintaining postrostatectomy urinary continence. Urology. 1996; 48:889-93.

10. Pastore AL, Palleschi G, Messas A, et al. Are early continence recovery and oncologic outcomes influenced by use of different devices in prostatic apex dissection during laparoscopic radical prostatectomy? J Endourol. 2014; 28:1313-9. 
11.Rassweiler J, Marrero R, Hammady A, et al. Transperitoneal laparoscopic radical prostatectomy: ascending technique. J Endourol. 2004; 18:593-9.

12. Rassweiler J, Hruza M, Frede T, Teber D. Laparoscopic extraperitoneal ascending nerve-sparing radical prostatectomy: an effective and safe technique for apical tumors. J Endourol. 2008; 22:2009-13

13. Van Velthoven RF, Ahlering TE, Peltier A, et al. Technique for laparoscopic running urethrovesical anastomosis: the single knot method. Urology. 2003; 61:699-702.

14. Sarle R, Tewari A, Hemal AK, Menon M. Robotic-assisted anatomic radical prostatectomy: Technical difficulties due to a large median lobe. Urol Int. 2005; 74:92-4.

15 Kalisvaart JF, Osann KE, Finley DS, Ornstein DK. Posterior reconstruction and anterior suspension with single anastomotic suture in robot-assisted laparoscopic radical prostatectomy: a simple method to improve early return of continence. J Robot Surg. 2009; 3:149-53

16. Hruza M, Weiss HO, Pini G, et al. Complications in 2200 Consecutive Laparoscopic Radical Prostatectomies: Standardised Evaluation and Analysis of Learning Curves. Eur Urol. 2010; 58:733-41.

17. Walz J, Gallina A, Saad F, et al.Nomogram predicting 10-year life expectancy in candidates for radical prostatectomy or radiotherapy for prostate cancer. J Clin Oncol. 2007; 25:3576-81.

18. Dindo D, Demartines N, Clavien PA. Classification of surgical complications: a new proposal with evaluation in a cohort of 6336 patients and results of a survey. Ann Surg. 2004; 240:205-13.

19. Anceschi U, Gaffi M, Molinari C, Anceschi C. Posterior reconstruction and outcomes of laparoscopic radical prostatectomy in a high-risk setting. JSLS. 2013; 17:535-42.

20. Smolski M, Esler RC, Turo R, et al. Bladder neck sparing in radical prostatectomy. Indian J Urol. 2013; 29:338-44.

21.Stolzenburg JU, Kallidonis P, Hicks J, et al. Effect of bladder neck preservation during endoscopic extraperitoneal radical prostatectomy on urinary continence. Urol Int. 2010; 85:135-8.

22. Chłosta PL, Drewa T, Jaskulski J, et al. Bladder neck preservation during classic laparoscopic radical prostatectomy - point of technique and preliminary results. WideochirInne Tech MaloInwazyjne. 2012; 7:89-95.

23. Koraitim MM. The male urethral sphincter complex revisited: An anatomical concept and its physiological correlate. J Urol. 2008; 179:1683-9

24. Shafik A. A study of the continence mechanism of the external urethral sphincter with identification of the voluntary urinary inhibition reflex. J Urol. 1999; 162:1967-71.

25. Tunc L, Gumustas H, Akin Y, et al. A novel surgical technique for preserving the bladder neck during robot-assisted laparoscopic radical prostatectomy: preliminary results. J Endourol. 2015; 29:186-91.

26. Rosenblatt A, Bollens R, Cohen EB. Extraperitoneal laparoscopic radical prostatectomy, In: Manual of Laparoscopic Urology, Springer-Verlag, ISBN 978-3-540-74726-0, 2008, Berlin Heidelberg, pp. 63-89.

27. Rocco F, Gadda F, Acquati P, et al. Personal research: reconstruction of the urethral striated sphincter. Arch Ital Urol Androl. 2001; 73:127-37.

28. Rocco B, Cozzi G, Spinelli MG, et al. Posterior musculofascial reconstruction after radical prostatectomy: a systematic review of the literature. Eur Urol. 2012; 62:779-90.

29. Daouacher G, Waldén M. A simple reconstruction of the posterior aspect of rhabdosphincter and sparing of puboprostatic collar reduces the time to early continence after laparoscopic radical prostatectomy. J Endourol. 2014; 28:481-6.

30. Poon M, Ruckle H, Bamshad BR, et al. Radical retropubic prostatectomy: Bladder neck preservation versus reconstruction. I Urol. 2000; 163:194-8.

31. Katz R, Salomon L, Hoznek A, et al. Positive surgical margins in laparoscopic radical prostatectomy: The impact of apical dissection, bladder neck remodeling and nerve preservation. J Urol. 2003; 169:2049-52.

32. Kadono Y, Ueno S, Kadomoto S, et al. Use of preoperative factors including urodynamic evaluations and nerve-sparing status for predicting urinary continence recovery after robot-assisted radical prostatectomy: Nerve-sparing technique contributes to the reduction of postprostatectomy incontinence. Neurourol Urodyn. Neurourol Urodyn. 2016; 35:1034-1039.

33. Kumar A, Samavedi S, Bates AS, et al. Age stratified comparative analysis of perioperative, functional and oncologic outcomes in patients after robot assisted radical prostatectomy--A propensity score matched study. Eur J Surg Oncol. 2015; 41:837-43.

34. Rassweiler J, Wagner AA, Moazin M, et al. Anatomic nervesparing laparoscopic radical prostatectomy: comparison of retrograde and antegrade techniques. Urology. 2006; 68:587-91.

\section{Correspondence}

Ali Serdar Gozen, MD, Associate Professor of Urology ali.goezen@slk-kliniken.de

Marcel Fiedler, MD marcel.fiedler@slk-kliniken.de Jens Rassweiler, MD, Professor of Urology jens.rassweiler@slk-kliniken.de Department of Urology, SLK-Klinikum Heilbronn, University of Heidelberg, Am Gesundbrunnen 20-26, D-74078 Heilbronn, Germany

Yigit Akin, MD, Associate Professor of Urology yigitakin@yahoo.com

Department of Urology, Izmir Katip Celebi University School of Medicine, 35060, Izmir, Turkey

Mutlu Ates, MD, Associate Professor of Urology

drmutluates@gmail.com

Department of Urology, Antalya Teaching and Research Hospital, 07059, Antalya, Turkey 